\title{
The Ethics of Disruptive Technologies: Towards a General Framework
}

Penultimate version. Final version forthcoming in: J.F. de Paz Santana and D.H. de la Iglesia eds. New Trends in Disruptive Technologies, Tech Ethics and Artificial Intelligence. Advances in Intelligent Systems and Computing. Springer (2022).

\author{
Jeroen Hopster ${ }^{10000-0001-9239-3048]}$ \\ ${ }^{1}$ University of Twente, Drienerlolaan 5, 7522 NB Enschede, The Netherlands \\ j.k.g.hopster@utwente.nl
}

\begin{abstract}
Disruptive technologies can be conceptualized in different ways. Depending on how they are conceptualized, different ethical issues come into play. This article contributes to a general framework to navigate the ethics of disruptive technologies. It proposes three basic distinctions to be included in such a framework. First, emerging technologies may instigate localized "first-order" disruptions, or systemic "second-order" disruptions. The ethical significance of these disruptions differs: first-order disruptions tend to be of modest ethical significance, whereas second-order disruptions are highly significant. Secondly, technologies may be classified as disruptive based on their technological features or based on their societal impact. Depending on which of these classifications one adopts and takes as the starting point of ethical inquiry, different ethical questions are foregrounded. Thirdly, the ethics of disruptive technology raises concerns at four different levels of technology assessment: the technology level, the artifact level, the application level, and the society level. The respective suitability of approaches in technology ethics to address concerns about disruptive technologies co-varies with the respective level of analysis. The article clarifies these distinctions, thereby laying some of the groundwork for an ethical framework tailored for assessing disruptive technologies.
\end{abstract}

Keywords: ethics of technology, emerging technologies, disruptive technology, systemic disruption, ethics of disruption

\section{$1 \quad$ Introduction}

The ethics of disruptive technologies is an emerging topic of academic interest. Scholarly initiatives that bear testimony to this claim include the overarching project in which the present research has been undertaken - the Dutch interuniversity research project Ethics of Socially Disruptive Technologies (ESDiT, 2020-2029) [1] - as well as the DiTTEt 2021 Proceedings [2], which is the venue of this article. Policymakers, too, are increasingly interested in the ethical dimensions of technological disruption. 
Consider the European Commission's legislative proposal for an Artificial Intelligence Act [3], in which the term "disruption" is used in several places, to highlight the Commission's aim of creating legal and social frameworks that are "resilient to disruption." Tech ethics and disruption are not just on the minds of scholars, but also high up on political agendas.

Yet whenever ethical discussions come to bear on "disruptive technologies", confusions abound. This is largely due to the fact that the concepts of "disruption" and "disruptive technologies" are widely used, but with different connotations, none of which is original to ethical scholarship itself. One influential usage goes back to the work of Clayton Christensen, who coined the term "disruptive technology" and popularized its use in the context of his disruptive innovation theory [4]. On Christensen's account, technologies should be designated as disruptive if they perform poorly as measured by initial consumer standards, but are able to overtake markets nonetheless, by scoring high on ancillary performance metrics that consumers subsequently begin to value. While certainly relevant to analyses of business and innovation, this understanding of disruptive technologies is not ideally suited for ethics. Its main drawback is that Christensen's conceptualization of disruptive technologies is strongly theory-laden - i.e. geared towards the theoretical framework of disruptive innovation theory - and somewhat idiosyncratic as a result. Indeed, various authors have criticized Christensen's conceptual framework [5,6], among others because it fails to capture colloquial intuitions about which technologies count as disruptive [7]. Christensen himself, too, became less eager to employ the term "disruptive technology" over the course of his career, and preferably referred to "disruptive innovation", flagging his own reservations about the appropriateness of the former concept in the context of disruptive innovation theory.

In the face of some of the limitations of Christensen's own rendering of disruptive technologies, alternative conceptualizations of disruptive technologies have emerged in recent years, which tend to be more ecumenical. On their broader understanding, disruptive technologies are simply those that displace existing technologies, shake industries, or create entirely new industries. [2] Various emerging technologies serve as examples here, such as AI, IoT, blockchain, 4G, CRISPR/Cas9 - some of the usual suspects in recent foresight reports shortlisting the anticipated disruptive technologies of the next years or decades $[8,9,10]$. Additionally, "digital disruption" has gained currency as a way of referring to the digital transformation of existing products and business models. [11] The emerging discourse on digital disruption diverges from Christensen's work by recentering scholarly discussions on technology (rather than innovation) and on the colloquial notion of disruption, with its broader connotations than Christensen's account. As such, digital disruption discourse has a better fit with the ethical domain, since ethical concerns are not - and should obviously not be rendered - sensitive to the peculiarities of disruption in Christensen's sense.

That said, the conceptual scope of recent work on digital disruption is still limited. Academic discussions of digital disruption are largely restricted to marketing and business studies, focusing on the disruption of consumer markets, industries, and business models. But technologies have the potential to disrupt much more than that. They can also disrupt institutions and social relations. Indeed, the archetypical 
disruptive technologies of the $21^{\text {st }}$ century are often ascribed a potential to fundamentally alter human nature and our place in the world. These kinds of disruptions are more salient in ethical terms, compared to disruptions of market and business models. Moreover, they are the kinds of disruptions that contemporary attempts at political legislation seek to address. Such legislation is typically not concerned with market disruptions in any strict sense, but rather with fundamental disruptions of human life and society, which the emerging technologies of our current age are anticipated to bring about.

Dissatisfied with this limited focus, some scholars have recently argued for a broader understanding of disruptive technologies, which pays tribute to its social, legal and political implications. Schuelke-Leech [12] makes the useful distinction between firstorder and second-order disruptions: whereas the former pertain to local market disruptions, the latter are associated with systematic disruptions at a much larger societal scale. Building on the ESDiT project [1], in my own work I have introduced the notion of "deep disruptions". These are disruptions that pertain to basic concepts and categories of thought, deeply held values and fixed points of human existence and normative interactions [13] - for instance, challenges to basic ethical concepts such as "autonomy" and "agency", or alterations of human capabilities and basic needs. While Schuelke-Leech's notion of second-order disruptions concerns the breadth of disruptive impacts - the various domains of social life that disruptive technologies affect - the depth of technological disruptions reflects technologies' capacity to fundamentally remake our society and ourselves in terms of our conceptual and ethical self-understanding. Broad as well as deep disruptions are obviously of great societal and ethical importance - and more so than first-order disruptions, which are the primary focus of the disruptive innovation and digital disruption frameworks. Hence, to the extent that the ethics of disruptive technologies limits itself to the narrow accounts of Christensen and his successors, it runs the risk of overlooking the most significant and pressing ethical issues.

Instead, a broader understanding of disruptive technologies is called for, with the dual aim of identifying core ethical concerns that technological disruption gives rise to, and of identifying and devising ethical approaches that can help to address such concerns. The aim of the present article is to outline some foundational distinctions that can help in generating an ethical framework specifically tailored for disruptive technologies in this broader sense. It does so in three steps. Section 2 elaborates on the abovementioned distinction between localized "first-order" disruptions and systemic "second-order" disruptions and explains why their ethical significance differs. Section 3 highlights that technologies may be classified as disruptive based on their technological features or based on their societal impacts. Depending on which of these classifications one adopts and takes as the starting point of ethical inquiry, different ethical questions arise and different ethical toolkits are needed. Section $\mathbf{4}$ distinguishes between four different levels at which ethical concerns raised by disruptive technologies can be identified and suggests that the suitability of different approaches in tech ethics depends, at least in part, on the target level of analysis. Section 5 concludes that the foregoing distinctions can assist ethicists and policymakers in 
coming up with a comprehensive framework for the ethical assessment of disruptive technologies.

\section{Localized vs. Systemic Disruptions}

In mapping the ethical landscape of disruptive technologies, Schuelke-Leech's [12] distinction between first- and second-order disruptions provides a helpful starting point. First-order disruptive technologies serve to transform markets and industries, but do so in localized fashion: changes are restricted to specific domains, and do not ripple through society. Consider the replacement in floppy-disks of ferrite heads and oxide disks by thin-filmed components during the 1980s. This constituted a technological disruption, that transformed the market of information storage [14]. But while this is a text-book example of a technological disruption, the disruption did not transform society at large: the impacts of the disruption were predominantly restricted to changes in the respective consumer domain.

Ethical issues that come into play regarding first-order disruptive technologies are domain-specific. How pronounced such issues are depends on the ethical significance of the respective domain, and the values that are at stake. Disruptions in the market of medical technologies, for instance, are likely to be ethically significant, as medical technologies tend to connect with morally laden issues regarding human health, longevity, well-being, equal access and vulnerability. Or consider Uber's disruption of the taxi market, which, too, may be regarded as a morally significant first-order disruptive innovation: the disappearance of standardized taxi-fees, and the changing availability of taxis in areas according to supply and demand, touches on issues of fairness and equal access.

Other first-order disruptive technologies have consumer impacts that are less morally significant. Consider the invention of single serve plastic coffee capsules in the 1990s [15]. This innovation has disrupted the coffee market, but as of yet it has not had any large-scale effects beyond that. Its ethical significance seems limited; the ease of preparing coffee is not a strong determinant of the quality of society. That said, the disruption is not entirely devoid of ethical significance. For instance, it has had effects on the labor market and on plastic waste production, which in turn are related to social and ethical values such as well-being and sustainability. While their ethically relevant impacts may be limited and indirect, one would be hard-pressed to find examples of first-order disruptions that are entirely devoid of ethical significance.

Yet the ethical significance of second-order disruptions is certainly more pronounced, and invariably so (Fig. 1). This should come as no surprise. Second-order disruptions arise through the interaction of multiple first-order disruptive technologies within a complex innovation ecosystem [12]. They serve to transform society at large, in large part as a consequence of unintended features and dynamics to which they give rise - dual use, technological unemployment, the merger with other technologies and with socio-economic developments, and so on. Consider the impact of blockchain technology, which ripple through society. Like the advanced floppy disk, blockchain has altered the fundamental techniques of storing public data. But it has also begun to 
alter practices in a range of other social domains, such as finance, administration, cybersecurity, industrial production, insurance, and public health [16]. The fact that they have a multiplicity of impact domains, thereby compromising basic architectures that strongly determine the quality of society, is what makes second-order disruptions highly significant in ethical terms. Given the different scope and nature of the ethical concerns that second-order disruptions give rise to - for instance regarding foresight, uncertainty, risk, value conflicts and incommensurability - it seems helpful to preserve the distinction between first- and second-order disruptions in ethical discourse.

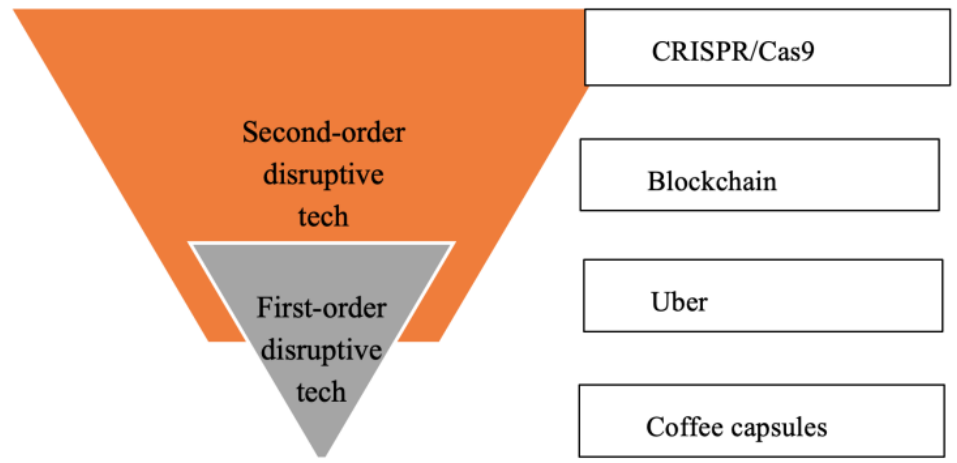

Fig. 1. The ethical significance of disruptive technologies.

One aspect of an ethics of disruptive technologies is to come up with an integrated ethical assessment of second-order disruptive technologies. By their very nature these technologies affect multiple social domains - and their impacts may be ethically desirable in some of them, but undesirable in others. The daunting yet important task for ethicists - as well as innovators - is to map the full breadth of domains that are implicated by the technology, both intendedly and unintendedly so. Subsequently, such information may be used as input for regulatory frameworks [3], and to give impetus to processes of responsible innovation and Value Sensitive Design (VSD) [17]. Given that social disruptions often come about with an overturning of existing institutions and regulatory checks and balances [18], an important further ethical task is to figure out which regulatory voids and responsibility gaps disruptive technologies give rise to, and how such gaps can be mended. Additionally, articulating an ethical framework for corporate social responsibility - even in the face of the uncertainty that disruption engenders - will be a core exercise to advance this subfield of tech ethics.

\section{Tech as Agent of Social Disruption vs. Tech Entangled in Social Disruption}

When analyzing socially disruptive technologies, there are two potential starting points of ethical assessment. On the one hand, we may start by looking at features of the technology in question and distill what makes them disruptive. This approach foregrounds the role of technology in instigating social disruption. Note that this 
involves the simplifying assumption that a technology can be inherently disruptive. Strictly speaking, this assumption is false: technologies are only disruptive in the context of a specific technological ecology or societal setting, which they serve to transform. Differently put, disruption is always tethered to a given technosocial context. That said, focusing on the "inherently disruptive" features of a technology can be a useful simplification, especially if the effects of the technology are (anticipated to be) invariant to a wide range of social contexts.

An alternative starting point is to first zoom in on the dynamics of a given disruption that is taking place in society, and subsequently flesh out which technologies are associated with this disruption. For instance, we might zoom in on the so-called "social credit system" being developed in China, and subsequently ponder how it is affected by emerging technologies, such as sensor technology and big data analytics. Hence, we move from an apparent social disruption to the technologies involved in it. Oftentimes, this will put the spotlights on a range of disruptive technologies, rather than just one of them. ${ }^{1}$

These different starting points serve to foreground somewhat different ethical issues. The first starting point brings to the fore ethical issues that have to do with the activity of disrupting, and places emphasis on the responsibility of tech-engineers as disruptors. How can disruptors be responsible innovators? Is it responsible to develop a potentially disruptive technological product in the first place? Such questions invite reflections that depart from design approaches in the ethics of technology [17]. Additionally, a focus on technologies and technological products is amenable to ethical foresight approaches [19]. What kinds of disruptions can we anticipate to occur, considering the specific features of a technology and the affordances it engenders?

The second, society-centered starting point foregrounds a different set of issues. It brings into focus questions of societal response and responsiveness. How do we design adequate social institutions and legal frameworks to cope with disruptions? How do we create a societal infrastructure that is resilient to emerging technologies, and helps to preserve core ethical values? The primary focus here is on questions of societal uptake, rather than technology design. Approaches in political philosophy and bioethics, among others, offer useful tools to broach these issues.

\footnotetext{
${ }^{1}$ Alternatively, the social credit system might itself be conceptualized as a (second-order) disruptive technology. Doing so presupposes a broad and implementation-oriented account of what "technology" can amount to (see section 4). The ethical focus, on this conceptualization, is with the broader dynamics of technosocial disruption.
} 


\section{A. Tech as agent of social disruption}

- Primary assessment: disruptive potential of technologies

- Features of a disruptive technology provide the starting point of ethical inquiry

- "Technologies" conceptualized in terms of technological artifacts, or fields of R\&D and their constitutitive techniques

- Focus on responsibility of innovators and disruptors

\section{B. Tech entangled in social disruption}

- Primary assessment: technological disruptions in society

- Technosocial disruptions provide the starting point of ethical inquiry

- "Technologies" often conceptualized in terms of technological applications, or contexts of implementation

- Focus on societal response to disruptions

Fig. 2. Two different ethical foci: (A) tech as social disruptor vs. (B) tech as implicated in processes social disruption.

In sum, we can distinguish between an "ethics of tech disruptors" and an "ethics of technosocial disruption." These need not be regarded as rivalling approaches: both have a legitimate place in the ethics of disruptive technologies. Depending on the kinds of ethical questions one wants to address, however, or the kind of regulatory framework one wants to devise, one approach may be better suited than the other.

\section{Four Levels of Ethical Analysis}

Many of the emerging and early adoption technologies which are arising and fusing in the current "fourth industrial revolution", such as AI, IoT, blockchain, additive manufacturing, 5G, sensor technology, advanced food technology, CRISPR/Cas9, neurotechnology and nanotechnology, have been described as disruptive technologies. The same holds for emerging or anticipated technologies that have potential to radically transform society in the further future, such as climate engineering, de-extinction, and quantum computing. These technologies comprise a rather diverse list: not only do they pertain to different domains, but the technologies are also described at different levels of granularity. In fact, they often seem to pertain to rather different kinds of entities.

Technology is an incredibly broad term, and it is not at all straightforward how to define it. The meaning of technology has changed over time [20], it has been conceptualized in myriad ways [21,22], and there is something of an emerging consensus that the term "technology" is polysemous [23]. Recent scholars have pinpointed at least three different basic referents of the term [24,25,26]:

a) The body of knowledge that constitutes a field of engineering.

b) The technical artifacts that a field of engineering gives rise to.

c) A set of applications that technical artifacts give rise to.

One might think of these as three distinct levels at which technologies can be identified and analyzed. While the entities referred to at each level may all be generically labelled "technologies", they clearly differ amongst each other.

In the field of technology ethics, a threefold classification of technologies along these lines is engrained in the framework of Anticipatory Technology Ethics (ATE), which is used to identify ethical issues regarding emerging technologies [25,26]. Within 
the ATE-approach, these levels are called a) the technology level, b) the artifact level, and c) the application level. These three levels of analysis correspond with the three abovementioned ways in which technologies can be conceptualized: in terms of the techniques they employ (e.g. additive manufacturing), in terms of their constitutive procedures and artifacts (e.g. bioplastics), or in terms of their applications (e.g. battlefield drones).

At each of these levels of description, different ethical issues arise. For purposes of the ethical assessment of emerging technologies, therefore, it is useful to hold these three levels distinct. ${ }^{2}$ In what follows, I follow the ATE-framework in providing a sketch of the ethics of disruptive technologies at each of these levels. I depart from the ATE-framework in including a fourth level of analysis - the society level - which focuses on the entire social context which is shaped in the co-evolutionary dynamics with emerging technologies. Taken together, these four levels of analysis provide a birds-eye's view of the landscape of disruptive technology ethics.

\subsection{The Technology Level}

First, consider the most general level of analysis - the technology level - which focuses on the basic material techniques involved in a technology, as developed, for instance, in fields of engineering, or deployed in medical intervention. Disruptions, at this level, have to do with features that are intrinsic to the techniques being employed, which are changing the respective fields of technology. Take CRISPR/Cas9, which is rapidly transforming the field of gene-editing, as it substantially improves on precursor geneediting techniques. In virtue of its constitutive techniques, CRISPR provides much greater precision in gene-editing, and it has made gene-editing a more effective and powerful tool. Yet it also brings along new kinds of unintended side-effects. For instance, it appears that when using CRIPSR in human embryos, unintended DNA changes adjacent to the target side can be brought about, which lead to unwanted genetic changes [27]. These accidental changes - which may be inherent side-effects of the technique itself - raise ethical worries about the technology as such.

\subsection{The Artifact Level}

Secondly, consider the artifact level. This level focuses on the usable products of a technology. This includes technical artifacts, such as bioplastics, as well as technical procedures, such as the process of carbon dioxide removal (CDR). Disruptions, at this level, have to do with features that are intrinsic to the respective artifacts and procedures. Take bioplastics, which are plastic materials produced from renewable organic matter. In virtue of their biochemical composition, bioplastics facilitate a more circular flow of material, making bioplastics a potential disruptor of the linear economy. CDR refers to the long-term removal, capture or sequestration of carbon dioxide $\left(\mathrm{CO}_{2}\right)$

2 Doing so can be difficult at times. There are boundary cases, in which it is not obvious what constitutes the appropriate level of description. This is a general challenge for the ATEframework. For present purposes, I gloss over this complication. 
from the atmosphere. By its very nature this procedure alters the planetary carbon cycle. As a result, CDR has potential to play a disruptive role in mitigating global warming.

\subsection{The Application Level}

Thirdly, consider the application level. This level is concerned with the concrete use of a technological artifact or procedure for a given purpose, or its configuration and implementation in a given context. For instance, battlefield drones are an application of drones in military contexts; care robots are a way of configuring robots for a specific set of tasks; smart cities involve the implementation of IoT and sensor technology in urban environments. Technological disruptiveness, at this level, is tied to contexts of use. Arguably, battlefield drones hold great potential to disrupt existing military practices, and care robots might have a similarly disruptive impact on existing systems of social care. Technological products create new affordances and constraints, thereby facilitating new social practices and altering existing ones. To the extent that these practices are rapidly transformed by emerging technologies, they may count as instances of social disruption.

\subsection{The Society Level}

Lastly, consider the societal level. This level looks at the general technosocial dynamics which are implicated by emerging technologies. For instance, smartphones have disrupted practices of human communication and information retrieval; deepfake technologies are disrupting systems of online trust and online identity. Sometimes, technologies are conceptualized directly in terms of their context of social implementation - one might speak, for instance, of "surveillance capitalism technologies" or "climate mitigation technologies". Disruption, at the society level, pertains to the breaking down of a stable historical trajectory, an entrenched state-ofaffairs, or a social equilibrium, for instance with regard to norms and institutions. There are various domains of societal impact that disruptive technologies might have. Broadly understood, these include not only the structure of society itself, but also disruptions to the natural and planetary environment.

\subsection{Ethical Approaches at Different Levels}

Which ethical approach had best be adopted to tackle questions of disruption? This depends, of course, on the nature of the questions at issue, and the aims of ethical inquiry. But arguably it also depends, at least in part, on which of the four levels I have outlined in this section is at stake. While for some purposes one might want to advance a comprehensive ethical analysis, which incorporates all four levels of analysis, one might also be concerned with an ethical issue at one specific level. The suitability of different approaches in technology ethics to address concerns about disruptive technologies co-varies with the level of analysis of concern: some approaches are particularly helpful at the technology level, others at the levels of artifact, application, or society. 
This differential suitability can be elucidated with reference to a central dilemma that the ethics of tech-disruption has to confront: the Collingridge-dilemma [28]. When a technology is at an early stage of development, it is still malleable and its direction of development can be influenced, but its effects on society are difficult to predict. When a technology is societally entrenched, its impacts have become clear, but it is now very difficult to alter the technology. Ethicists therefore face a choice: do they tailor their approaches to the early stages of technology development, accepting uncertainty about the technology's eventual deployment, or do they tailor their approaches the later stage of societal implementation, accepting that it will be very difficult to alter the technology at this point?

Different approaches in technology ethics can be understood as providing different answers to this question [29]. The aptitude of these answers, in turn, depends in part on the level of analysis at which ethical concerns play out. Consider four families of approaches in technology ethics:

i) Ethical foresight approaches [19], such as the aforementioned ATE-approach $[25,26]$;

ii) Ethical design approaches, such as the VSD-approach [17];

iii) Ethical mediation approaches, such as the Technological Mediation approach [30];

iv) Ethical experimentation approaches, such as the Sociotechnical Experimentation approach [31].

Foresight approaches tend to be most useful at the technology and artifact level. At the society level foresight approaches become exceedingly difficult, as the dynamics of societal uptake are incredibly complex and difficult to anticipate. Design ethics approaches, by contrast, are difficult to apply at the most basic level of R\&D. These approaches are more readily invoked at the artifact and application levels. Moral mediation approaches have a more concrete and implementation-based focus still. They most naturally lend themselves for analysis at the application level, where users interact with technologies. Lastly, sociotechnical experimentation approaches are most readily invoked at the society level, where foresight is extremely difficult. Rather than speculating about what might occur, this approach looks at "social experiments" actually taking place in society and seeks to ethically accompany and regulate them. 


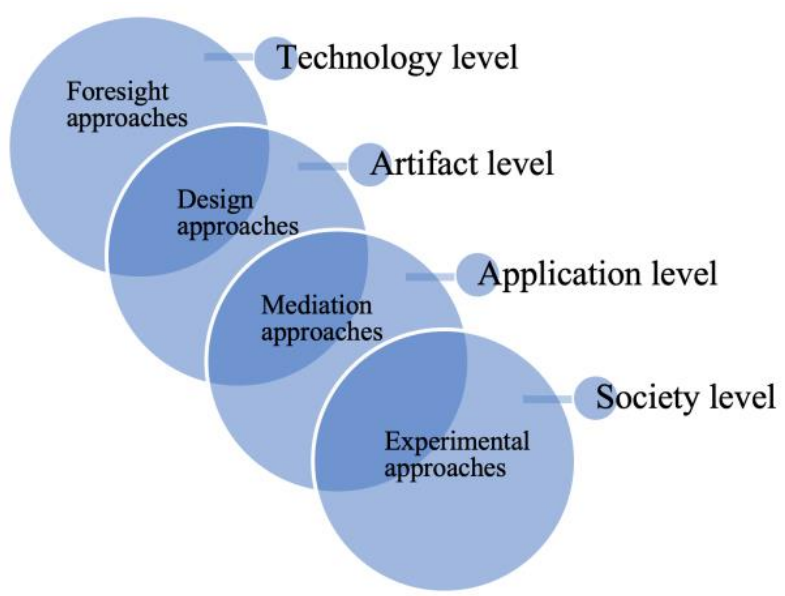

Fig. 3. The respective strengths of different families of approaches in technology ethics. These approaches can be regarded as providing different answers to the Collingridgedilemma.

This overview should not be taken to imply that said approaches should be confined to the respective levels, at least not in any strict sense. Instead, the point is that as ethical tools, they are specifically well adapted for assessment at some levels, and less so at others - albeit with ample overlap. This ties in with the suggestion that these approaches are not exclusive but complementary. They - together with several other approaches that have been developed in the ethics of technology, and in the field of ethics more generally - are part of the pluralist arsenal of approaches that ethicists can adopt to scrutinize disruptive technologies.

\section{Conclusion}

This article has outlined three basic distinctions that can help one to navigate the ethics of disruptive technologies. To what extent does this analysis suggest that disruptive technologies constitute a distinct class, that merits specific ethical concern? Some of the distinctions outlined above, such as the four different levels technology analysis presented in section four, pertain to the ethics of emerging technologies more generally. Yet others are specific to issues concerning disruptive technologies. This holds for the distinction between first- and second-order disruptions, as well as the distinction between technologies as instigators of disruption, versus technologies as components in the broader dynamics of technosocial disruption. A next step is to work out these basic distinctions into more fully-fledged normative assessment frameworks. Hence, future efforts to further develop the ethics of disruptive technologies as a of subfield of technology ethics should be encouraged. Such efforts are likely to benefit the work of ethicists and policymakers, on a topic of great societal importance. 


\section{References}

1. Brey, P., Roeser, S., IJsselsteijn, W., et al.: Ethics of Socially Disruptive Technologies. Project proposal for Netherlands Organisation of Scientific Research (2019). www.esdt.nl

2. DiTTEt, 2021: Proceedings of the first International Conference on Disruptive Technologies, Tech Ethics and Artificial Intelligence. To be published in: Advances in Intelligent Systems and Computing. Springer.

3. European Commission: Proposal for a Regulation of the European Parliament and of the Council laying down Harmonised Rules on Artificial Intelligence (Artificial Intelligence Act) and Amending certain Union Legislative Acts. 21 April 2021. Retrieved from: https://digital-strategy.ec.europa.eu/en/library/proposal-regulation-laying-downharmonised-rules-artificial-intelligence

4. Christensen, C.M.: The Innovator's Dilemma: The Revolutionary Book that Will Change the Way You Do. Business. Harvard Business School Press, Boston (1997).

5. Utterback J.M, Acee, H.J.: Disruptive Technologies: An Expanded View. International Journal of Innovation Management 9(1), 1-17 (2005).

6. Tellis, G.J.: Disruptive Technology or Visionary Leadership? The Journal of Product Innovation Management 23, 34-38 (2006).

7. Gobble, M.M.: Defining Disruptive Innovation. Research-Technology Management 59(4), 66-71 (2016).

8. DNV: Technology Outlook 2030 (2019). Retrieved from: https://www.dnv.com/to2030/overview/index.html

9. WCO: Study Report on Disruptive Technologies (2019). Retreived from:: http://www.wcoomd.org/-/media/wco/public/global/pdf/topics/facilitation/instrumentsand-tools/tools/disruptivetechnologies/wco_disruptive_technologies_en.pdf?la=en

10. OECD: Science, Technology and Innovation Outlook (2016). Paris: OECD Publishing.

11. Skog, D.A., Wimelius, H., Sandberg, J.: Digital Disruption. Business and Information Systems Engineering 60(5), 431-437 (2018).

12. Schuelke-Leech, B: A Model for Understanding the Orders of Magnitude of Disruptive Technologies. Technological Forecasting \& Social Change 129, 261-274 (2018).

13. Hopster, J.K.G.: What are Socially Disruptive Technologies? Technology in Society 67: 101750 (2021).

14. Bower J.L., Christensen C.M.: Disruptive Technologies: Catching the Wave. Harvard Business Review 73(1), 506-520 (1995).

15. González, A: Single-serve Coffee Revolution brews Industry Change. The Seattle Times, February 15, 2014. Retrieved from: http://www.seattletimes.com/business/single-servecoffee-revolution-brews-industry-change/

16. Frizzo-Barker, J., Chow-White, P.A., Adams, P.R., Mentanko, J., Ha, D., Green, S.: Blockchain as a Disruptive Technology for Business: A Systematic Review. International Journal of Information Management 51, 102029 (2014).

17. Friedman, B., Kahn, P.H.J., Borning, A.: Value Sensitive Design and Information Systems. In: Zhang P., Galletta D., (eds.): Human-computer Interaction in Management Information Systems: Foundations 5, 348-372). ME Sharpe, Armonk (2006).

18. Wessel, M., Helmer, N.: A Crisis of Ethics in Technology Innovation. MIT Sloan Management Review, 61(3), 71-76 (2020).

19. Floridi, L., Strait, A.: Ethical Foresight Analysis: What It Is and Why It Is Needed? Minds \& Machines 30, 77-97 (2020).

20. Schatzberg E.: Technology: Critical History of a Concept. University of Chicago Press, Chicago (2018). 
21. Mitcham C.: Thinking Through Technology: The Path Between Engineering and Philosophy. University of Chicago Press, Chicago (1994).

22. Meijers, A. ed.: Philosophy of Technology and Engineering Sciences. Elsevier (2009).

23. Carlsen, H., Dreborg, K.H., Godman, M., Hansson, S.O., Johansson, L., Wikman-Svahn, P.: Assessing Socially Disruptive Technological Change. Technology in Society 32, 209-218 (2010).

24. Stahl, B.C., Heersmink, R., Goujon, P., Flick, C., van den Hoven, J., Wakunuma, K.J., Ikonen, V., Rader, M.: Identifying the Ethics of Emerging Information and Communication Technologies: An Essay on Issues, Concepts and Method. International Journal of Technoethics 1(4), 20-38 (2010).

25. Brey P.: Anticipatory Ethics for Emerging Technologies. Nanoethics 6(1), 1-13 (2012).

26. Brey P.: Ethics of Emerging Technologies. In: Hansson S.O., ed.: Methods for the Ethics of Technology. Rowman and Littlefield International, 175-192 (2017).

27. Frosch, J.: Genome Editing in Human Embryos has Unintended Side-effects. Bionews (2020). Retrieved from: https://www.bionews.org.uk/page_150490

28. Collingridge, D.: The Social Control of Technology. St. Martin's Press, New York (1980).

29. Kudina, O., Verbeek, P.P.: Ethics from Within: Google Glass, the Collingridge Dilemma, and the Mediated Value of Privacy. Science, Technology \& Human Values 44(2), 291-314 (2019).

30. Verbeek, P.P. Moralizing Technology: Understanding and Designing the Morality of Things. University of Chicago Press, Chicago (2011).

31. Van de Poel, I.: Why New Technologies should be Conceived as Social Experiments. Ethics, Policy \& Environment 16(3), 352-55 (2013). 